\title{
DUSTFALL EFFECT ON HYPERSPECTRAL INVERSION OF CHLOROPHYLL CONTENT- A LABORATORY EXPERIMENT
}

\author{
Chen Yuteng ${ }^{1}$, Ma Baodong ${ }^{1 *}$, Li Xuexin ${ }^{1}$, Zhang Song ${ }^{1}$, Wu Lixin ${ }^{2}$ \\ ${ }^{1}$ Department of Surveying and mapping engineering, Northeastern University, 110819, Shenyang, Liaoning, China \\ mabaodong_rs@126.com \\ ${ }^{2}$ School of Geoscience and Info-Physics, Central South University, 410083, Changsha, Hunan, China
}

KEY WORDS: Dustfall, Hyperspectral, Chlorophyll Content, Vegetation Index, Inversion Accuracy

\begin{abstract}
:
Dust pollution is serious in many areas of China. It is of great significance to estimate chlorophyll content of vegetation accurately by hyperspectral remote sensing for assessing the vegetation growth status and monitoring the ecological environment in dusty areas. By using selected vegetation indices including Medium Resolution Imaging Spectrometer Terrestrial Chlorophyll Index (MTCI), Double Difference Index (DD) and Red Edge Position Index (REP), chlorophyll inversion models were built to study the accuracy of hyperspectral inversion of chlorophyll content based on a laboratory experiment. The results show that: (1) REP exponential model has the most stable accuracy for inversion of chlorophyll content in dusty environment. When dustfall amount is less than $80 \mathrm{~g} / \mathrm{m}^{2}$, the inversion accuracy based on REP is stable with the variation of dustfall amount. When dustfall amount is greater than $80 \mathrm{~g} / \mathrm{m}^{2}$, the inversion accuracy is slightly fluctuation. (2) Inversion accuracy of DD is worst among three models. (3) MTCI logarithm model has high inversion accuracy when dustfall amount is less than $80 \mathrm{~g} / \mathrm{m}^{2}$; When dustfall amount is greater than $80 \mathrm{~g} / \mathrm{m}^{2}$, inversion accuracy decreases regularly and inversion accuracy of modified MTCI (mMTCI) increases significantly. The results provide experimental basis and theoretical reference for hyperspectral remote sensing inversion of chlorophyll content.
\end{abstract}

\section{INTRODUCTION}

Due to environmental disruption, dust has become one of the main pollutants that affect the quality of air in China (Qiao et al., 2011). Dust can spread in a long distance and cause adverse effects in surrounding ecological environment (Peng et al., 2013). Vegetation is one of the best indicators to reflect the quality of the regional ecological environment (Ma et al., 2010). Chlorophyll is the dominant pigment in plant photosynthesis, and it could reflect plant photosynthetic ability, physiological stress, carbon fixation capacity and nitrogen utilization efficiency (Jiang et al., 2016). Monitoring vegetation and its related biological systems can provide decision-making basis for protecting the ecological environment (Koppnen et al., 2002). The change of chlorophyll content will affect the spectral curve of vegetation, which make it possible to use remote sensing data to estimate chlorophyll content. Therefore, chlorophyll is an important index to evaluate the growth of vegetation, and monitoring of chlorophyll content is of great significance to the construction and protection of ecological environment.

Getting physiological parameters of plants by traditional method is manual collection, with heavy workload and low efficiency. The development of remote sensing technology provides a new scientific means for the extraction of vegetation information. Inversion of vegetation parameters based on hyperspectral remote sensing data has become a hot topic in the field of vegetation ecology (Cheng et al., 2015). Hyperspectral index has been proved to be universal in the retrieval of chlorophyll density for different vegetation types and growth stages (Zhang et al., 2013). Zhao et al. (Zhao et al, 2004) used partial least squares regression to construct a regression model of canopy spectrum and chlorophyll content in winter wheat. A model between chlorophyll content and reflectance spectra of wheat canopy in the range of $400-750 \mathrm{~nm}$ by using hyperspectral technique was set up and proved that it had a good effect (Ji et al., 2007). Yang et al. (Yang et al., 2010) used the $\mathrm{MSAVI}_{2}$ index and the spectral reflectance at the wavelength of $800 \mathrm{~nm}$ to estimate the leaf area and chlorophyll density of wheat and rice respectively. Diouf et al.(Diouf et al., 2013) used neurovariational method to estimate the chlorophyll of the sea surface.

Dust which covers the foliage of vegetation changes the spectral characteristics of vegetation ( $\mathrm{Li}$ et al., 2008). Some scholars have studied the relationship between dustfall and vegetation spectra. Yan et al. (Yan et al., 2015) utilized remote sensing and ground-based spectral data to assess dustfall distribution in urban areas. Tan et al. (Tan et al., 2013) used hyperspectral technology to determine the reflectance of the mining area, and revealed the most seriously dust contaminated areas. Variation of spectral characteristics of plant leaves in dusty environment was analyzed and an inversion model for the dustfall of iron tail mineral powder was established by $\mathrm{Xu}$ et al. (Xu et al.,2017). Wang et al. (Wang et al., 2012) analyzed the change of the reflectance spectra and the first derivative spectra of dedusting before and after around dedusting. Peng et al. (Peng et al., 2013) established a hyperspectral remote sensing model for monitoring dustfall on elm leaves with a high accuracy.

At present, most researches use vegetation spectral reflectance to estimate chlorophyll to judge vegetation growth status. However, the effect of dustfall on remote sensing inversion accuracy of vegetation chlorophyll content has been not studied. Dustfall coverage leads to changes in spectral characteristics of leaves, which would reduce hyperspectral inversion accuracy of chlorophyll content. Anshan, located in Liaoning Province, is one of the largest iron and steel bases in China and has proven iron reserves about 9 billion tons (Jiang et al., 2007). With the increasing of iron ore mining and iron tailings emission, the dust pollution around the Anshan mining area is serious. The tailings ponds in the east and south of Anshan are under the 
leading wind direction. Thus, dustfall amount in the surrounding area far exceeds the standard of $8 \mathrm{t} / \mathrm{km}^{2}$ per month (Wang et al., 2014). The purpose of this paper is to study of the dustfall effect on chlorophyll content inversion by using samples from Anshan. The final aim is to improve the inversion accuracy of chlorophyll content by hyperspectral remote sensing in dusty environment.

\section{MATERIAL AND METHOD}

\subsection{Sample collection}

Boston ivy leaf in the mining area was selected as the experimental leaf sample. It was fixed on the horizontal platform of experimental test immediately after being picked. The dustfall sample was collected from Qidashan tailings pond in Anshan Iron and Steel Group. The main elements include $82.28 \% \mathrm{SiO}_{2}, 9.90 \% \mathrm{TFe}, 1.62 \% \mathrm{FeO}, 0.85 \% \mathrm{MgO}, 0.73 \%$ $\mathrm{Al}_{2} \mathrm{O}_{3}, 0.66 \% \mathrm{CaO}$. Particle size of experimental dustfall is less than $100 \mu \mathrm{m}$.

The dustfall amount difference of this experiment was $8 \mathrm{~g} / \mathrm{m}^{2}$. There were 21 groups of dustfall amount from $0 \mathrm{~g} / \mathrm{m}^{2}$ to 160 $\mathrm{g} / \mathrm{m}^{2}$.

\subsection{Measurement of chlorophyll content and spectra}

The content of chlorophyll was measured by SPAD-502 measuring instrument. 5-7 points were collected evenly on each leaf, and the mean value of SPAD was used. The SPAD value is a dimensionless ratio. SPAD-502 measuring instrument has been applied in many fields for its simple to operation (Francisco et al., 2009). SPAD meter readings are positively correlated to actual chlorophyll content (Song et al., 2017; Uddling et al., 2007). So SPAD value was used to characterize the chlorophyll content of the leaves in this experiment.

In this experiment, the SVC HR-1024 spectrometer (350-2500 $\mathrm{nm})$ was used to collect the spectral information of the leaves. The spectral resolution of SVC HR-1024 spectrometer in the range of $350-1000 \mathrm{~nm}$ is $3.5 \mathrm{~nm}$, and the spectral resolution of $1000-1850 \mathrm{~nm}$ is $9.5 \mathrm{~nm}$, and the spectral resolution of 1850 $2500 \mathrm{~nm}$ is $6.5 \mathrm{~nm}$. The experimental light source was halogen lamp, and elevating angle was 60 degrees, and the distance was $50 \mathrm{~cm}$, and the spectrometer time was $2 \mathrm{~s}$. Using 4 degree lens, the leaf was located at the bottom of the lens, and the height was set to $55 \mathrm{~cm}$ from the leaf height to lens. The spectral curves of 32 dust-free leaves samples were collected in turn. Then we selected 6 leaves (marked as No.1-6) from the 32 leaves. Then dustfall experiment was carried out. A total of 21 sets of spectral test curves were obtained for each leaf.

\subsection{Data processing}

In this study, a statistical model was established to estimate chlorophyll content. The correlation between chlorophyll content and vegetation indices of 32 leaves was analysed to select the best inversion model. After testing, the Medium Resolution Imaging Spectrometer Terrestrial Chlorophyll Index (MTCI) (Dash et al., 2004) logarithmic model, the Double Difference Index (DD) (Maire et al., 2004) model and the REP (Red Edge Position) index model were selected for the next step. The fitting formula is shown in Table 1.

In this study, the relative error is used as the indicator of the inversion accuracy of chlorophyll content.

$$
R E=\frac{\left|y_{i}-y_{o}\right|}{y_{o}}
$$

where $y_{i}$ is the predictive value of chlorophyll content, and $y_{o}$ is the measured value of chlorophyll content. The smaller the RE value is, the higher inversion accuracy is.

\begin{tabular}{lll}
\hline $\begin{array}{l}\text { Vegetation } \\
\text { index }\end{array}$ & Regression equation & $\mathrm{R}^{2}$ \\
\hline MTCI & $\mathrm{y}=23.932 \ln \mathrm{x}+28.285$ & 0.9177 \\
DD & $\mathrm{y}=31.095 \mathrm{e}^{0.0404 \mathrm{x}}$ & 0.9514 \\
REP & $\mathrm{y}=7 \mathrm{E}-08 \mathrm{e}^{0.0285 \mathrm{x}}$ & 0.7457 \\
\hline
\end{tabular}

Table 1. Inversion model of chlorophyll content

REP is the inflexion point in the red edge region (680 to $780 \mathrm{~nm}$ ) of the spectral reflectance signature. The expressions of MTCI and DD are as follows(Table 2.):

\begin{tabular}{lll}
\hline Index & Formula & References \\
\hline MTCI & $\left(\mathrm{R}_{753}-\mathrm{R}_{708}\right) /\left(\mathrm{R}_{708}-\mathrm{R}_{681}\right)$ & Dash et al., 2004 \\
DD & $\left(\mathrm{R}_{749}-\mathrm{R}_{720}\right)-\left(\mathrm{R}_{701}-\mathrm{R}_{672}\right)$ & Maire et al., 2004 \\
REP & The position of the inflexion & Cho et al., 2006 \\
& point in the red region & \\
\hline
\end{tabular}

Table 2. Summary of vegetation indices

\section{RESULTS AND ANALYSIS}

\subsection{Effect of dustfall amount on the spectral characteristics}

As the dustfall amount increases, the difference of spectral curves between the dusty leaves and dustfall gradually decreases (Fig.1). In band of 380-710 nm, the reflectivity of the dustfall leaves is greater than dust-free leaves. As dustfall amount increases, the leaf reflectivity of visible light also increases. The wave peak at $559 \mathrm{~nm}$ gradually tends to flat. In $710-1420 \mathrm{~nm}$ band, the reflectivity of the dust-free leaves is greater than dustfall leaves, and the reflectance decreases with the increasing of the dustfall amount. In band of 1420-1572 nm, the reflectivity of the dusty leaves is greater than the dust-free leaves.

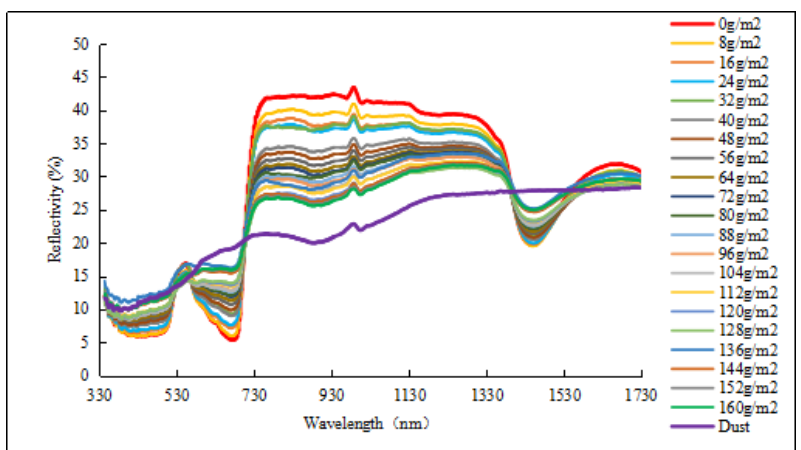

Fig. 1. Leaf reflectivity curve varies with dustfall amount. 


\subsection{Dustfall effect on inversion accuracy of chlorophyll content}

The result shows that the MTCI logarithmic model has high inversion accuracy when dustfall amount is less than $80 \mathrm{~g} / \mathrm{m}^{2}$ (Figure 2.). The inversion accuracy of the MTCI logarithmic model decreases obviously when dustfall amount is in the range of $80-160 \mathrm{~g} / \mathrm{m}^{2}$.

With increasing of dustfall amount, the inversion accuracy of DD exponential model decreases obviously.

The REP exponential model has high inversion accuracy for chlorophyll content in dusty environment, and the stability of inversion accuracy is highest among the three models.

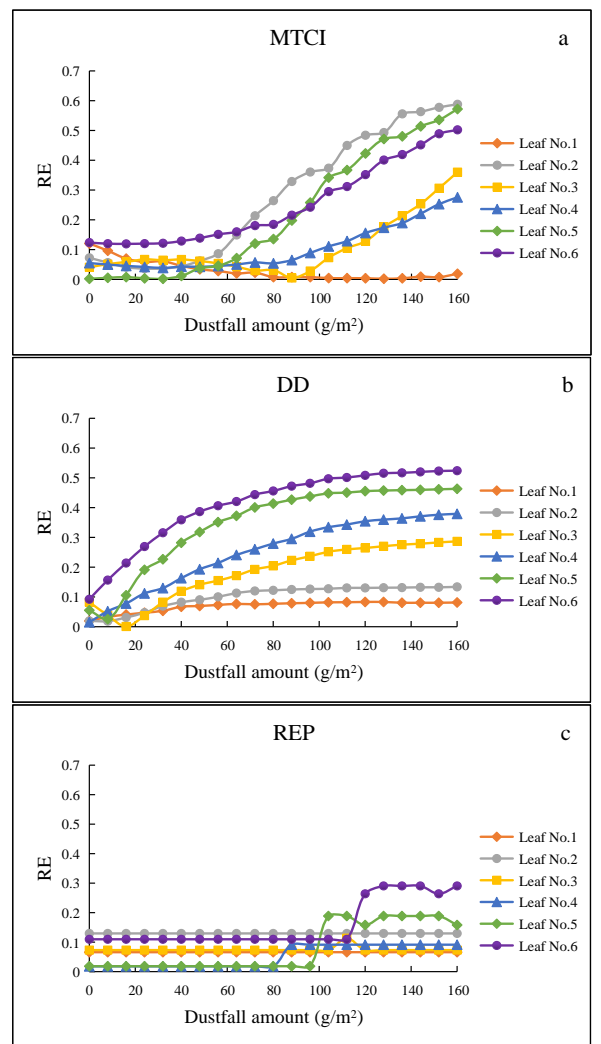

Fig. 2. Inversion accuracy varies with dustfall amount. (a)

MTCI, (b) DD, (c) REP.

\subsection{Effect of dustfall on REP}

REP is sensitive to the change of chlorophyll content, and it is an important vegetation index for the inversion of chlorophyll content in hyperspectral remote sensing. As shown in Figure 2, the inversion accuracy of chlorophyll content in REP is the most stable in this experiment. Therefore, it is necessary to further analysis the relationship between REP and dustfall amount.

According to the study of Peng (Peng et al., 2013) and Li (Li et al., 2016), there is no obvious effect on REP in dusty environment. In this study, when the dustfall content is less than $80 \mathrm{~g} / \mathrm{m}^{2}$, REP has no obvious change. However, when the dustfall amount is greater than $80 \mathrm{~g} / \mathrm{m}^{2}$, REP is slightly fluctuating (Figure 3.). According to analysis, the reason is that REP is related to chlorophyll content. While dustfall covers leaves, it does not actually changes chlorophyll content of leaves. As dustfall amount increases, the REP fluctuates slightly.
After calculation, the maximum value of first derivative of iron tailing dustfall reflectance in the red edge region $(670-760 \mathrm{~nm})$ is 0.048 , which is located at $699 \mathrm{~nm}$. The first order of the reflectivity of the red edge of the dust-free leaves are 0.957 1.058 , which are far greater than the reflectivity of dustfall. Because the calculation of the reflection model is complex, a simplified expression is used to represent:

$$
E=E_{l}+E_{d}
$$

where $E$ is the total reflected energy of the dustfall, and $E_{1}$ is the reflection energy of the leaf, and $E_{d}$ is the energy reflected by the dustfall. The total energy of the incident is constant, so the change trend of the reflection energy $E$ is equivalent to the change trend of the reflectivity. When the amount of dustfall is small, the reflected energy $E$ is mainly the reflection energy $E_{1}$ of the leaves. In addition, the first order of the reflectance in red edge region $(670 \mathrm{~nm}-760 \mathrm{~nm})$ is much larger than the dustfall. Therefore, when dustfall amount is small, the REP will not change obviously. As dustfall amount increases, $\mathrm{E}_{1}$ decreases while the proportion of $E_{d}$ increases gradually. When $E_{l}$ approaches 0 , the dusty leaves would fully display the spectral characteristics of the dustfall.

In the end, REP of dust leaves tends to be $699 \mathrm{~nm}$. Therefore, in this study, the REP of dusty leaves does not change obviously when the dustfall amount is less than $80 \mathrm{~g} / \mathrm{m}^{2}$, and REP changes slightly when the dustfall amount is greater than $80 \mathrm{~g} / \mathrm{m}^{2}$.

In this study, the REP index model not only has high inversion accuracy on chlorophyll content, but also has very stable inversion accuracy for chlorophyll content in dusty environment The reason is that the REP is very sensitive to the change of chlorophyll content, and dustfall has no obvious effect on REP. Therefore, in the three models, the REP exponential model has the most stable inversion accuracy for chlorophyll content in dusty environment.

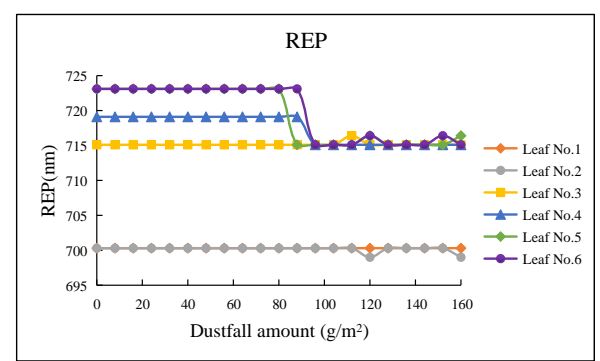

Fig. 3. REP varies with dustfall amount.

\subsection{The correction of the MTCI index}

According to the results from the dustfall experiment, REP index model has best stability for the inversion accuracy of chlorophyll content while the stability of DD index model is the worst. The MTCI logarithmic model takes about $80 \mathrm{~g} / \mathrm{m}^{2}$ as the critical point. The MTCI logarithmic model still has high inversion accuracy when dustfall amount is less than $80 \mathrm{~g} / \mathrm{m}^{2}$. Inversion accuracy of chlorophyll content decreases regularly when dustfall amount is greater than $80 \mathrm{~g} / \mathrm{m}^{2}$. According to study of Dash et al. (Dash et al., 2007), MTCI has high sensitivity to chlorophyll content, and could inhibit the influence of background and atmospheric changes. Moreover, the accuracy of MTCI in the high chlorophyll-content range is higher than REP. In addition, the MTCI index is simpler than the REP calculation, and the unique value can be obtained after 
setting wavelengths. Therefore, in order to improve the inversion accuracy of MTCI model in dusty environment, a modified MTCI (mMTCI) is designed according to the statistical data:

$$
m M T C I=m \bullet M T C I
$$

where $\mathrm{m}$ is a correction factor.

The No. 1-6 leaves were divided into two groups, of which No. 1,3 and 5 were used as modeling group, and the 2, 4 and 6 were used as the verification group. After tested, the best expression for determining the $\mathrm{m}$ value is as follows:

$$
m=8 \times 10^{-5} x^{2}-0.0036 x+1
$$

where $\mathrm{x}$ is dustfall amount.

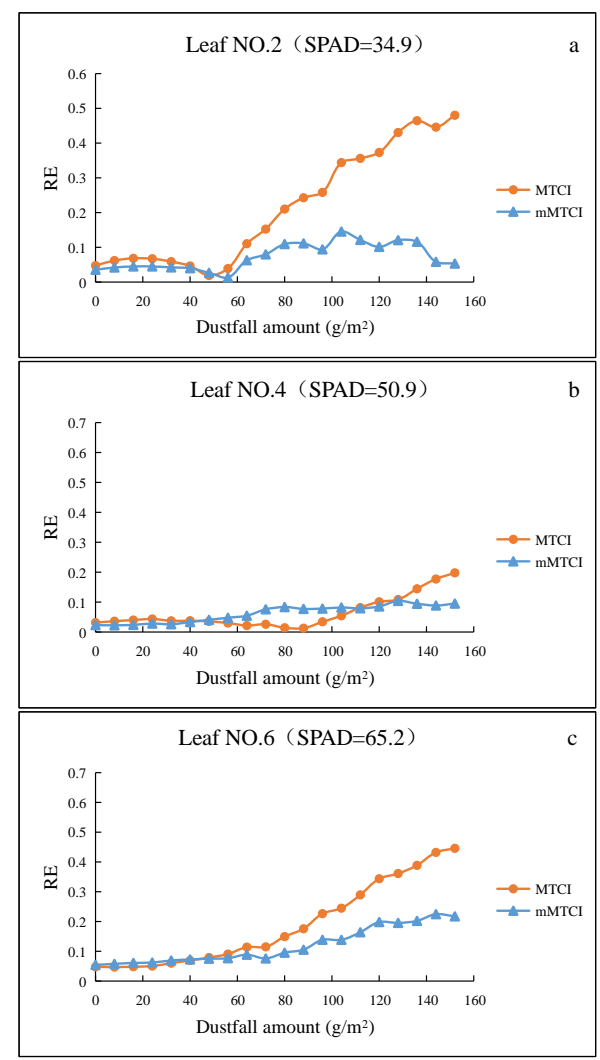

Fig. 4. MTCI and mMTCI model inversion accuracy varies with dustfall amount. (a) Leaf NO.2, (b) Leaf NO.4, (c) Leaf NO.6.

\section{CONCLUSION}

By analyzing the three indices (MTCI, DD and REP) in laboratory experiment, the conclusions can be summarized as follows:

(1) With the increasing of dustfall amount, the dustfall characteristics of the iron tailings increases gradually. When dustfall amount is less than $80 \mathrm{~g} / \mathrm{m}^{2}$, the REP is not obvious change. When dustfall amount is more than $80 \mathrm{~g} / \mathrm{m}^{2}$, the REP fluctuates slightly. The REP exponential model has a high inversion accuracy for chlorophyll content in dusty environment $\left(0-160 \mathrm{~g} / \mathrm{m}^{2}\right)$. The inversion accuracy of REP is the most stable among three indices.
(2) The DD exponential model has a high inversion accuracy for chlorophyll content of the dust-free leaves, but the accuracy obviously decreases in dusty environment. The DD exponential model is the least effective for inversion of chlorophyll content among three inversion models.

(3) The MTCI logarithmic model has a high inversion accuracy when dustfall amount is less than $80 \mathrm{~g} / \mathrm{m}^{2}$. The inversion accuracy decreases gradually when the dustfall amount is greater than $80 \mathrm{~g} / \mathrm{m}^{2}$. Inversion accuracy of modified MTCI (mMTCI) increases significantly when dustfall amount is 80 $160 \mathrm{~g} / \mathrm{m}^{2}$.

\section{ACKNOWLEDGEMENTS}

This research is jointly supported by the Fundamental Research Funds for the Central Universities (N160104006), and the National Natural Science Foundation of China (41201359).

\section{REFERENCES}

Cheng, Z.Q., Zhang, J.S. Meng, Ping., 2015. Improvement of algorithm used for extraction hyperspectral feature bands of vegetation. Transactions of the Chinese Society of Agricultural Engineering. 31(12), pp.179-185.

Cho, M.A., Skidmore, A.K., 2006. A new technique for extracting the red edge position from hyperspectral data: The linear extrapolation method. Remote Sensing of Environment. 101(2), pp.181-193.

Dash, J., Curran, P.J., 2004. The MERIS terrestrial chlorophyll index. International Journal of Remote Sensing. 25 (23), pp.5403-5413.

Dash, J., Curran, P.J., 2007. Evaluation of the MERIS terrestrial chlorophyll index (MTCI). Advances in Space Research, 39 (1) , pp.100-104.

Diouf, D., Niang A, Brajard, J., 2013. Retrieving aerosol characteristics and sea-surface chlorophyll from satellite ocean color multi-spectral sensors using a neuralvariational method. Remote Sensing of Environment. 130(4), pp.74-86.

Francisco, H. Ruiz-Espinoza, Bernardo, M., 2010. Field evaluation of the relation between chlorophyll content in basil leaves and a portable chlorophyll meter (SPAD-502) readings. Journal of Plant Nutrition. 33 (3), pp.423-438.

Ji, Y.H., Wang, P.X., Yan, T.L., 2007. Estimations of Chlorophyll and Water Contents in Live Leaf of Winter Wheat with Reflectance Spectroscopy. Spectroscopy and Spectral Analysis. 27 (3), pp.514-516.

Jiang, H.L., Zhang, L.F. 2016. Research on Spectral Scale Effect in the Estimation of Vegetationn Leaf Chlorophyll Content. Spectroscopy and Spectral Analysis. 36(1), pp169176.

Jiang, Y.Y., Yang, Y.G., Li, W.B., 2007. Status of iron ore resource exploitation in Anshan area and some suggestions. Mining Engineering. (2)pp.26-29.

Koppnen, S., Pulliainen, J. 2002. Lake water quality classification with airborne hyperspectral spectrometer and 
simulated MERES data. Remote Sensing of Environment. 79(1), pp.51-59.

Li, D.R., 2008. An introduction to Photogrammetry and Remote sensing. Sino Maps.

Li, W., Wu, L., Chen, T., 2016. Hyperspectral estimation model of dustfall deposition content on plant leaves. Transactions of the Chinese Society of Agricultural Engineering, (6), pp.180185.

Ma, C., Wu, W.B., 2010. Analysis and Extracts of Vegetation Coverage Changes of Fuxin Region. Geomatics \& Spatial Information Technology. 33(1), pp78-80.

Maire, G. L., François, C., Dufrêne, E., 2004. Towards universal broad leaf chlorophyll indices using PROSPECT simulated database and hyperspectral reflectance measurements. Remote Sensing of Environment. 89 (1), pp.128.

Peng, J., Xiang, H.Y., Wang, J.Q., 2013. Quantitative model of foliar dustfallfall content using hyperspectral remote sensing. Journal of Infrared and Millimeter Waves. 32(4), pp.31.

Qiao, Y.S., 2011. Research Progress of the Inhalable Particular in the Urban Air. Environmental Monitoring in China. 27(2), pp.22-26.

Song, T.Y., Cheng, Y., Zhao, R., 2017. Analysis on correlation between leaves SPAD value and chlorophyll content of flowering Chinese Cabbage. Journal of Northeast Agricultural Sciences. 42(2), pp.34-37.

Tan, D. J., Xie, J., Jian, L., 2013. Analysis on spectral characteristics of dust polluted crops in Wansheng coal mineing district. Remote Sensing for Land and Resources. 25(2), pp.121-130.

Xu, A., Ma, B.D., Li, X.C., Wu, L.X., 2017. Spectral testing and quantitative inversion for dust of iron tailings on leaf. Remote Sensing for Land and Resources. 29(1), pp.164-169.

Uddling J., Gelangalfredsson, J., Piikki, K., 2007. Evaluating the relationship between leaf chlorophyll concentration and SPAD-502 chlorophyll meter readings. Photosynthesis Research .91 (1),pp.37-46.

Wang, J.W., 2014. Reflections on transtion planning of old industfallrial base cities in northeast China: taking the comprehensive plan of Anshan city as an example. City Planing. S2, pp.105-113.

Wang, T., Liu, Y., Wu, H.Y., 2012. Influence of foliar dust on crop reflectance spectrum and nitrogen monitoring. Spectroscopy \& Spectral Analysis. 32(7), pp.1895.

Yan, X., Shi, W., Zhao, W., 2015. Mapping dustfall distribution in urban areas using remote sensing and ground spectral data. Science of the Total Environment. 507, pp.604-12.

Yang, F., Fan, Y.M., Li, J.L., 2010. Estimating LAI and CCD of rice and wheat using hyperspectral remote sensing data. Transactions of the CSAE. 26(2), pp.237-243.

Zhang, S., Liu, L.Y., 2013. Inversion of Canopy Chlorophyll Density Based on Hyperpectral Vegetation Indices. Remote Sensing Information. 28 (3), pp.94-101+111.
Zhao, X., Liu, S.H., 2004. A Method for Inverting Chlorophyll Content of Wheat Using Hyperspectral. Geography and GeoInformation Science. 20(3), pp.36-39. 